Boise State University

ScholarWorks

Geosciences Faculty Publications and

Presentations

Department of Geosciences

$2-2020$

\title{
High-Velocity Surface Layer Effects on Rayleigh Waves: Recommendations for Improved Shear-Wave Velocity Modeling
}

\author{
Gabriel Gribler \\ Boise State University \\ Lee M. Liberty \\ Boise State University \\ T. Dylan Mikesell \\ Boise State University
}

This is an author-produced, peer-reviewed version of this article. The final, definitive version of this document can be found online at Bulletin of the Seismological Society of America, published by Seismological Society of America. Copyright restrictions may apply. https://doi.org/10.1785/0120190120. The content of this document may vary from the final published version. 
This is an author-produced, peer-reviewed version of this article. The final, definitive version of this document can be found online at Bulletin of the Seismological Society of America, published by Seismological Society of America. Copyright restrictions may apply. https:// doi.org/10.1785/0120190120. The content of this document may vary from the final published version.

\title{
High velocity surface layer effects on Rayleigh waves:
}

\section{Recommendations for an improved shear wave velocity model}

\author{
Gabriel Gribler ${ }^{1}$, Lee M. Liberty ${ }^{1}$, and T. Dylan Mikesell ${ }^{1}$ \\ ${ }^{1}$ Department of Geosciences, Boise State University, Boise, Idaho, USA
}

October 9, 2019

\begin{abstract}
Soil stiffness estimates are critical to geologic hazard and risk assessment in urban centers. Multichannel analysis of surface wave (MASW) data collection along city streets is now a standard, costeffective, and non-invasive soil stiffness approximation tool. With this approach, shear wave velocities (Vs) are derived from Rayleigh wave signals. While the current MASW practice is to neglect the effect of a high-velocity road layer on soil Vs estimates, our models show measurable impacts on Rayleigh wave amplitudes and phase velocities when seismic data are acquired on a road surface. Here, we compare synthetic models to field MASW and downhole Vs measurements. Our modeling indicates that a road layer attenuates Rayleigh wave signals across all frequencies, introduces coherent higher mode signals, and leads to overestimated Vs and Vs30 values. We show that Vs30 can be overestimated by more than $7 \%$ when soft soils underlie a rigid road surface. Inaccurate Vs estimates can lead to improper soil classification and bias earthquake site response estimates. For road-based MASW data analysis, we recommend incorporating a surface road layer in the Rayleigh wave inversion to improve Vs estimate accuracy with depth.
\end{abstract}

\section{Introduction}

Site-based measurement of soil or rock properties is critical for the design of both new construction and for building retrofits. Shear wave velocities (Vs) directly relate to soil stiffness, and can be used to estimate local weak and strong earthquake ground motions (e.g., Aki, 1993; Kramer, 1996) and soil deformation potential (e.g., Andrus and Stokoe II, 2000; Kayen et al., 2013). Thus, a standard characterization practice is to estimate Vs to a depth of 10 to $30 \mathrm{~m}$, either through direct downhole measurements (e.g., Robertson 
This is an author-produced, peer-reviewed version of this article. The final, definitive version of this document can be found online at Bulletin of the Seismological Society of America, published by Seismological Society of America. Copyright restrictions may apply. https:// doi.org/10.1785/0120190120. The content of this document may vary from the final published version.

et al., 1986) or through surface-based measurements. The downhole seismic measurement approach can be expensive and provides only one-dimensional Vs estimates to borehole depths. The multi-channel analysis of surface wave (MASW) active-source surface seismic approach (McMechan and Yedlin, 1981; Song et al., 1989; Park et al., 1999) has been shown to approximate Vs with depth in one dimension (Park et al., 1999; Stephenson et al., 2005) and is useful for non-invasive and rapid measurements. Traditionally, active source surveys rely on geophone coupling to firm soil. While this approach is feasible in undeveloped areas, it is often not practical in urban areas where native materials lie beneath a paved surface. To estimate soil stiffness in developed landscapes, the seismic land streamer MASW approach, where the source and receiver(s) are directly coupled to a road surface, is now a common acquisition method (e.g., Van Der Veen et al., 1999; Van der Veen et al., 2001; Pugin et al., 2004; Liberty and Gribler, 2014). Here, we explore the impact of Vs estimates in the presence of a paved surface layer, specifically to estimate high frequency site response and soil structure beneath urban centers.

Inazaki (2006) compared active source seismic data acquired on a road surface to data acquired on native materials adjacent to the road. While they noted a relative decrease in surface wave amplitude while acquiring data on the road, Inazaki (2006) did not quantify these amplitude effects. Foti et al. (2018) noted greater coherence of higher mode surface waves at higher frequencies compared to fundamental mode signals in the presence of a rigid surface layer, but they did not explore the phase velocity effects on the resulting soil stiffness or Vs profile estimates. Through modeling and field data analysis, we explore the effect of a road surface on Rayleigh wave amplitude, dispersion, and inversion-derived Vs estimates. We compare MASW data collected through downtown Salt Lake City via a seismic weight drop/land streamer system (Liberty et al., 2018) to Vs estimates derived from downhole seismic cone penetration test (SCPT) data (McDonald and Ashland, 2008). These SCPT data are assumed to be ground truth, as they offer accurate Vs estimates, with errors ranging from 1-3\% in unconsolidated sediments (Moss, 2008). We generate synthetic Rayleigh wave dispersion data from the SCPT data and then modify the upper 10 to $25 \mathrm{~cm} \mathrm{Vs} \mathrm{to} \mathrm{simulate} \mathrm{different}$ road conditions. We forward model dispersion data to quantify phase velocity and amplitude changes as a function of frequency for the different Vs models. We then make recommendations to best estimate Vs with depth from MASW data acquired on a road surface. Here, we use the National Earthquake Hazard Reduction Program (NEHRP) site classifications for both field and modeled data (BSSC, 2009).

This paper is organized in the following manner. We first introduce the two types of (common) road compositions that we consider in this study. We then introduce the modeled and field acquisition geometry, as well as soil properties. Using numerical modeling, we investigate the effects due to different road surfaces on the amplitude and phase velocity of Rayleigh waves and the eventual Vs models estimated by phase velocity inversion. Finally, we discuss the potential for incorrect site classification due to neglecting the road 
This is an author-produced, peer-reviewed version of this article. The final, definitive version of this document can be found online at Bulletin of the Seismological Society of America, published by Seismological Society of America. Copyright restrictions may apply. https:// doi.org/10.1785/0120190120. The content of this document may vary from the final published version.

surface and we quantify the potential for phase velocity bias with frequency based on the natural material beneath the road surface. We specifically highlight the road effects on soft soils, where Vs overestimation is greatest.

\section{Road properties}

While a wide range of road designs and materials are used in construction, we focus our models on two road designs that commonly comprise city streets (Yoder and Witczak, 1975). We define a rigid road as a layer that contains a binder (commonly cement) within a crushed aggregate base. This design is topped with an asphalt surface. A rigid road is commonly used for high-traffic city streets, as it offers many of the strength and load carrying capabilities of concrete, but is simple and cost effective to construct. A flexible road provides less support when compared to a rigid road, as it has no binder in the crushed aggregate base layer. This layer is also topped with an asphalt surface, and is commonly used for low-traffic neighborhood roads and parking lots. Physical property estimates, including Vs, of the two modeled road types are outlined in Nazarian et al. (1988). Here we model 1) a rigid $25 \mathrm{~cm}$ thick road layer with $\mathrm{Vs}=1300 \mathrm{~m} / \mathrm{s}$ and 2) a flexible $10 \mathrm{~cm}$ thick road layer with $\mathrm{Vs}=800 \mathrm{~m} / \mathrm{s}$. For both road types, we use a Poisson ratio of 0.40 and a density of $2100 \mathrm{~kg} / \mathrm{m}^{3}$. While we model both road surface conditions, our field data were collected on a road surface that best matches a rigid high-traffic city road (Liberty et al., 2018).

\section{Seismic acquisition and model parameters}

Our models simulate seismic data acquired upon soft and stiff soils of the Salt Lake basin (e.g. McDonald and Ashland, 2008). Our modeled and field acquisition geometry consist of 48 vertically oriented geophones, spaced $1.25 \mathrm{~m}$ apart, with an impulsive seismic source located $5 \mathrm{~m}$ from the nearest geophone. We base our model and field comparisons on co-located SCPT and surface-seismic MASW measurements. The shallow stratigraphy at the field site consists of alternating fine- and course-grained lacustrine and alluvium (Personius and Scott, 1992), and the depth to groundwater is within the upper few meters. For comparison to surface seismic measurements, we use borehole 146 (McDonald and Ashland, 2008), where SCPT derived Vs ranges from 120 to $220 \mathrm{~m} / \mathrm{s}$ in the upper $30 \mathrm{~m}$, with relatively stiff NEHRP Class D soils (Vs>200 m/s) between 2 to $5 \mathrm{~m}$ depth and 21 to $25 \mathrm{~m}$ depth (Figure 1). SCPT results suggest NEHRP Class E soils $(\mathrm{Vs}<180 \mathrm{~m} / \mathrm{s}$ ) at the surface, between 5 to $15 \mathrm{~m}$ depth, and 21 to $28 \mathrm{~m}$ depth. This site is classified as NEHRP site class E with an average Vs for the upper 30 meters (Vs30) of $170 \mathrm{~m} / \mathrm{s}$. 
This is an author-produced, peer-reviewed version of this article. The final, definitive version of this document can be found online at Bulletin of the Seismological Society of America, published by Seismological Society of America. Copyright restrictions may apply. https:// doi.org/10.1785/0120190120. The content of this document may vary from the final published version.

\section{Numerical modeling}

To explore road-surface effects on MASW-derived Vs estimates, we model Rayleigh wave propagation in a seven-layer 1-D velocity model simplified from the SCPT measurements in borehole 146 (dashed-red line in Figure 1). We use the generalized reflection and transmission $(\mathrm{R} / \mathrm{T})$ coefficient forward modeling method (Kennett, 1974; Kennett and Kerry, 1979; Pei et al., 2008, 2009; Kennett, 2009) to calculate theoretical dispersion curves for fundamental and higher mode Rayleigh waves. We then model the waveform time series, which contain only Rayleigh wave energy, using 1-D modeling code from Michaels and Smith (1997) and Michaels (2018). We model waveforms for three cases: 1) native materials; 2) the same as (1) with an additional $25 \mathrm{~cm}$ thick rigid road surface; 3 ) the same as (1) with an additional $10 \mathrm{~cm}$ flexible road surface. We first compare the seismic power spectra from the synthetic waveforms in each model (Figure 2). We then compare dispersion derived from the synthetic model shot gathers to dispersion derived from a field record located adjacent to borehole 146 (Figure 3).

\section{Spectral power analysis}

To investigate the road-surface effect on seismic power spectra, we calculate the total signal power by applying the Fast Fourier Transform to each seismic waveform and summing over all receivers. We show the 3-40 Hz power spectra for the synthetic models, with and without the road layer, in Figure 2. Compared to the native material model, we observe an approximate peak seismic power reduction of 2.5 orders of magnitude when we include a rigid $25 \mathrm{~cm}$ thick road layer (Figure 2). In the model with a $10 \mathrm{~cm}$ thick flexible road surface, we observe a similar power spectra reduction between 25-40 Hz as compared to the rigid road model. However, at lower frequencies the power is only reduced by about one order of magnitude when compared to the native material model. Although we do not show the amplitude effects from other velocity models, our modeling indicates an increasing amplitude reduction with increasing velocity contrast between the road material and the underlying strata. We attribute this reduction in seismic power to an increase in Young's modulus of the surface layer, reducing the resulting stress exerted on the underlying native material from the fixed force source.

In summary, both the rigid and flexible road surface models reduce power spectra amplitudes compared to the native material model, with the greatest power decrease observed in the rigid road surface model at frequencies below $25 \mathrm{~Hz}$. This result is consistent with field observations (e.g. Inazaki, 2006), and we conclude that the Rayleigh wave amplitude is strongly related to shallow subsurface properties and the velocity contrast with the underlying strata. To compensate for amplitude attenuation, a larger seismic source may be needed on rigid or flexible road surfaces when compared to data collection on native materials. 
This is an author-produced, peer-reviewed version of this article. The final, definitive version of this document can be found online at Bulletin of the Seismological Society of America, published by Seismological Society of America. Copyright restrictions may apply. https:// doi.org/10.1785/0120190120. The content of this document may vary from the final published version.

However, the amplitude of other coherent signals may also change with different shallow velocity models, so noise amplitudes may also vary. Field testing should confirm whether adequate coherent surface wave signals are consistently generated while acquiring data on a road surface.

\section{Phase velocity analysis}

In addition to the influence of the road surface on amplitude, we investigate the road surface influence on phase velocity dispersion of the Rayleigh wave. Using the seven-layer SCPT-derived native material model (Figure 1), we generate 3-40 Hz theoretical dispersion images and dispersion curves (Figure 3a). We then generate dispersion images and dispersion curves for two eight-layer models; the seven-layer model SCPT-derived model plus the additional rigid or flexible road layer (Figure 3b and c, respectively). While we focus on fundamental mode energy in our analysis, we recognize that higher mode signals impact the fundamental mode coherence and dispersion curve picks. Therefore, for our waveform modeling, we include the first and second higher modes with the MASW-derived dispersion images and we plot these theoretical dispersion curves. We explore both phase velocities with frequency, and changing patterns of coherence in the dispersion images. We scale each image by the peak amplitude in each image.

Our first observation is that the theoretical fundamental mode dispersion curves differ across each model, while the higher mode curves remain mostly unchanged (Figure 3). This suggests that the thin road surface minimally impacts higher mode phase velocities for our models. However, although the higher mode phase velocities are consistent between models, we observe that varying higher mode coherence influences the fundamental mode coherence through interference. This interference is best observed on the rigid road model, where the peak coherence for frequencies greater than $20 \mathrm{~Hz}$ is associated with higher mode signals (Figure 3b). For the native material and flexible road surface models, we observe little interference between the fundamental and higher modes, and the majority of the energy coherence in both images tracks the fundamental model dispersion curves (Figure 3a and c, respectively). We relate this difference to lower coherence higher modes compared to the fundamental mode amplitudes for the native and flexible road models and conclude that the high-frequency fundamental mode coherence is compromised in the rigid road layer due to higher mode interference.

To compare the three modeled dispersion curves to each other and to our MASW field data, we plot the calculated theoretical dispersion curves for the fundamental mode on a dispersion image obtained from a shot gather that lies adjacent to SCPT borehole 146 (Figure 3d). (Recall that the theoretical curves come from the smoothed SCPT model at borehole 146.) The MASW data were acquired on a high traffic road surface and should best match the results from rigid road surface. The three curves show that the road surface 
models, with $25 \mathrm{~cm}$ rigid and $10 \mathrm{~cm}$ flexible layers, exhibit an increase in phase velocity across all frequencies when compared the native material model. At frequencies between 5 and $10 \mathrm{~Hz}$, we observe a $10 \%$ phase velocity increase due to the presence of either road surface. This difference decreases slightly between 10 and $20 \mathrm{~Hz}$. At frequencies above $\sim 20 \mathrm{~Hz}$, the fundamental mode phase velocity diverges for each model, and above $30 \mathrm{~Hz}$, the phase velocity differences among the models level off, with the rigid and flexible models showing velocity increases of $\sim 30 \%$ and $\sim 12 \%$, respectively, compared to the native material model. Note that the theoretical dispersion from the rigid road surface model displays very little velocity variability at frequencies above $20 \mathrm{~Hz}$. This suggests that if a user inverted dispersion picks above $\sim 25 \mathrm{~Hz}$ in the presence of a road surface layer, the likely result would be a smooth and overestimated Vs depth profile at shallow depths, compared to data acquired on native material. We note that coherence of the fundamental mode signal on the field record diminishes above $\sim 22 \mathrm{~Hz}$ (Figure 3d). This coherence pattern is most similar to the $25 \mathrm{~cm}$ rigid road surface model where higher modes dominate the dispersion image (Figure 3b). Therefore, above this frequency, mode mis-identification is possible and the shallow velocity structure is masked by road layer effects. Below $\sim 22 \mathrm{~Hz}$ we observe the highest coherence trend tracking more closely to the models with the road surface included (Figure 3d). Therefore, we conclude that Vs differences in the top 10 or $25 \mathrm{~cm}$ impact phase velocity picks at all frequencies, resulting in an overestimation of the Vs model for depths well below the road layer.

\section{Estimation of Vs with depth}

The purpose of this section is to determine the role that neglecting the road surface plays in the final Vs depth profile. In this section, we invert the theoretical fundamental mode dispersion curves for the native material and rigid road surface models using the genetic algorithm (GA). We use the GA because it offers a robust approach to estimate Vs with depth (Yamanaka and Ishida, 1996; Dal Moro et al., 2007). For the GA inversion, we set upper and lower bounds on all parameters being estimated and five generations of 500 individuals are run (total of 2500 trial models). We compare all of the resulting inverse models to the seven-layer SCPT-derived model from borehole 146, which has Vs30=170 m/s and is classified as a class E soft soil site (BSSC, 2009). The forward model that we use in the genetic algorithm is the same R/T method used to generate the theoretical dispersion curves (Figure 3). For the dispersion inversion, we allow both depth and Vs to vary for each layer. For computational savings and inversion consistency, we set the bounds on velocity to vary by plus or minus $20 \%$ and layer thicknesses to vary by plus or minus $10 \%$, compared to the true model. The data used in the inversion are the theoretical dispersion curves outlined in Figure 3 from 4-35 Hz. This limited pass band reduces the potential for shallow guided wave effects producing instabilities 
This is an author-produced, peer-reviewed version of this article. The final, definitive version of this document can be found online at Bulletin of the Seismological Society of America, published by Seismological Society of America. Copyright restrictions may apply. https:// doi.org/10.1785/0120190120. The content of this document may vary from the final published version.

in our forward model. We note that while we are using noise-free theoretical dispersion curves, the inversion problem itself is highly non-unique. Therefore, we do not expect to perfectly recover the Vs depth model. We do, however, expect to observe similar general trends in the profiles (i.e. gross structure like Vs10 or Vs30). To quantify the error associated with the inversion, we run 12 iterations for each GA inversion, and calculate the mean and one standard deviation of the resulting velocity profiles (Figure 3a-c).

We begin by comparing the SCPT-derived Vs model to the inversion result derived from dispersion curve picks obtained using the same model (Figure 3a). The resulting Vs velocity inversion with the GA is very similar to the true model, with the non-unique inversion producing slight velocity differences as depth increases (Figure 4a). Due to limited frequency information, we observe an increasing misfit between observed and calculated Vs models at depths greater than 15 meters. This is specifically related to low frequencies, and we observe this increase in uncertainty in both the field and synthetic data inversions (e.g., Foti et al., 2018; Liberty et al., 2018). To compare bulk Vs values, we plot the average Vs with depth (e.g. the values corresponding to 30 meters depth represent Vs30) (Figure 4e). This plot shows that the average Vs through the entire depth range agrees with the true model. The inverted model yields a Vs30 of $172 \mathrm{~m} / \mathrm{s}$, a $1.1 \%$ overestimation compared to the smoothed SCPT model. While slightly different, this model still falls within a classification of site class E soil.

We next examine the effects introduced by collecting data on a road surface, but neglecting the road surface in the inversion (Figure 4b). When we compare this seven-layer Vs model to the SCPT-derived model, we note an overestimation of Vs, especially in the upper 15 meters. The average Vs poorly matches the SCPT model in the upper 15 meters where a velocity inversion is mapped. Moreover, the average Vs is overestimated at all depths (Figure 4e), and we observe upwards of $20 \%$ overestimation of average Vs in the upper two meters, while Vs for depths below $5 \mathrm{~m}$ is overestimated by $\sim 10 \%$ (Figure $4 \mathrm{f}$ ). We observe a Vs30 difference of $7.6 \%$ compared to the SCPT model and a Vs30 of $183 \mathrm{~m} / \mathrm{s}$, or site class D stiff soils (Figure 4e). Thus, neglecting the high velocity road layer in the inversion has changed the site classification for this model.

To accommodate a road layer in our inversion, we fix our first layer to the thickness and velocity of the road material and we retain seven-layers in our soil model (Figure 4c). With this road-surface constraint, we observe a better match to the SCPT-derived Vs model, now very similar to the inversion of native materials (Figure $4 \mathrm{~d}$ ). Average Vs differences in the upper few meters are reduced to $\sim 3 \%$ when compared to the native model (Figure 4f) and the Vs30 difference is now 1.7\% (Figure 4e). By including the rigid road layer in the inversion, Vs30 now measures $173 \mathrm{~m} / \mathrm{s}$, and the site class E soil type closely matches the SCPT-derived Vs values. This suggests that by including the road surface in our inversion, we better match absolute and depth-averaged Vs values. We note that this requires accurate a priori knowledge of the road thickness 
and road Vs to obtain an accurate Vs profile with the MASW inversion. Without direct road thickness measurements from engineering logs, destructive coring methods, or through methods like high frequency dispersion analyses (Nazarian et al., 1988), we suggest examining a range of forward models, that include differing road layer properties to recognize the effects of, and compensate for, the road layer effect. We do not treat this model examination further though.

\section{Road surface influence on field data}

We acquired shot records with a seismic land streamer and accelerated weight drop source along a five $\mathrm{km}$ long profile of 700 South road in Salt Lake City, Utah, USA (Liberty et al., 2018). Because Vs generally increases from west to east across the profile (McDonald and Ashland, 2008), we can compare Vs derived from field dispersion images, modeled with and without a road layer. We select shot gathers from a $1.6 \mathrm{~km}$ long portion of 700 South, where we observe a transition from site class E soils to site Class D soils (Figure 5). We generated five to seven dispersion images from shots within $10 \mathrm{~m}$ of a mid-point location at ten locations spaced about $200 \mathrm{~m}$ apart. For our inversion, we first neglect the rigid road surface layer and invert using a seven-layer Vs model to $30 \mathrm{~m}$ depth. We then add a rigid road layer between the surface and $25 \mathrm{~cm}$ depth with a $\mathrm{Vs}=1300 \mathrm{~m} / \mathrm{s}$, then re-invert the data. We plot error bars representing one standard deviation from the sets of neighboring inversions, showing the variability between adjacent data and the inversion results.

Consistent with our numerical modeling results, we observe that by not including the road layer in the inversion, we overestimate Vs30 values by 5 to 10\% (Figure 5). We observe an overestimate of about 10\% for the shots where site Class E soils are mapped, and we observe an overestimate of about $5 \%$ for the shots where site Class D soils are mapped. More importantly, the Vs30 values that include a road layer match boreholes 146 and 147 SCPT-derived Vs30 measurements that were obtained along the streamer profile (McDonald and Ashland, 2008). Our analysis demonstrates that if the road surface is not accounted for, the transition from E class sediments $(V s 30<180 \mathrm{~m} / \mathrm{s})$ to D class sediments $(180 \mathrm{~m} / \mathrm{s}<\mathrm{Vs} 30<360 \mathrm{~m} / \mathrm{s})$ shifts to the east by one city blocks (about $200 \mathrm{~m}$ distance). Considering that this transition is located within a rapidly expanding urban corridor, the road corrections are critical to include in the MASW inversion analysis. If a road layer is not included in Vs inversions within urban corridors, the uncertainty in site class boundaries should be increased due to Vs30 values being biased to higher values.

\section{Site Classification Bias}

While the inversion approach illustrates the limitations of using MASW to characterize Vs structure with depth, we obtain more accurate depth averaged Vs30 estimates in the numerical models by accounting for a 
This is an author-produced, peer-reviewed version of this article. The final, definitive version of this document can be found online at Bulletin of the Seismological Society of America, published by Seismological Society of America. Copyright restrictions may apply. https:// doi.org/10.1785/0120190120. The content of this document may vary from the final published version.

rigid road surface in the inversion. Now, we explore a range of Vs starting models (from class E to class B) to determine how a rigid surface layer influences Vs30 site classification. We compare theoretical dispersion curves for models with and without a $25 \mathrm{~cm}$ thick rigid road layer and calculate the percent difference in phase velocity for frequencies from 3 to $80 \mathrm{~Hz}$ (Figure 6). We use eight models, each with a Vs gradient of $+4 \mathrm{~m} / \mathrm{s}$ per meter. Each model contains a different Vs at the surface $\left(\mathrm{V}_{o}\right)$ and extends to $100 \mathrm{~m}$ depth. We model to $100 \mathrm{~m}$ depth to address the high velocity models at low frequencies, but we mostly focus on the different Vs30 site class or subclass as defined by Wills et al. (2000).

Our models show that the phase velocity is faster across the entire frequency band when the 25 -cm thick rigid road layer is included in the model. The greatest phase velocity difference in the rigid road models occurs at the slowest Vs values (Figure 6). For example, we observe a $20 \%$ phase velocity overestimation from 20 to $80 \mathrm{~Hz}$ when the original Vs30 is $155 \mathrm{~m} / \mathrm{s}$ (site class E). For starting models with higher average Vs30 (e.g. classes B and C), the road surface influence is less pronounced. Once Vs30 is greater than $760 \mathrm{~m} / \mathrm{s}$ (site class B), phase velocities differ by less than $3 \%$. These results indicate that for lower velocity materials (i.e. site class E and D), the road layer is significant and should be included in the inversion to accurately estimate Vs30 or other average Vs values. Conversely, for faster velocity materials (NEHRP class C and B), the dispersion curve is less sensitive to a fast surface layer.

To compare the influence of the $10 \mathrm{~cm}$ thick flexible road surface $(\mathrm{Vs}=800 \mathrm{~m} / \mathrm{s})$, we repeat this analysis, but only for the two end member models of site class E and B (Figure 6). For low Vs (site class E), we again observe a frequency dependent phase velocity difference, with nearly a $20 \%$ difference at frequencies above $60 \mathrm{~Hz}$ and an $8 \%$ difference near $10 \mathrm{~Hz}$. For high Vs material (site class B), we observe no discernible difference in the phase velocities. We conclude that for thin flexible road surfaces, the road surface effect is negligible when the underlying native material has high Vs, but is significant and important to consider when low Vs values underlie any road surface (flexible or rigid).

\section{Conclusion}

In urban environments, we are often limited to collecting active-source seismic data on paved roads. Paved roads act as a thin high Vs surface layer, but this layer is typically neglected when estimating the underlying Vs by inverting Rayleigh wave dispersion curve data. Here we demonstrate that a thin road surface can have a large effect on surface wave amplitude, velocity dispersion, and higher mode coherence. Modeling seismic data on a thin road layer, we observe a two and a half order of magnitude decrease in seismic power. This suggests that in a low signal-to-noise environment, a larger seismic source or additional data stacking (e.g. more hammer hits) may be needed with the MASW approach to attain acceptable data 
This is an author-produced, peer-reviewed version of this article. The final, definitive version of this document can be found online at Bulletin of the Seismological Society of America, published by Seismological Society of America. Copyright restrictions may apply. https:// doi.org/10.1785/0120190120. The content of this document may vary from the final published version.

quality. More importantly, the Rayleigh wave phase velocities are faster across all modeled frequencies when imaging through a road, leading to an overestimation in Vs with depth. To address this velocity difference, we recommend the addition of a high-velocity surface layer in the Rayleigh wave inversion. In our example, we find that the Vs30 is overestimated by approximately $10 \%$ because of a $25 \mathrm{~cm}$ thick high-velocity road layer. In addition, the road surface can produce higher mode dispersion interference that may result in incorrect fundamental mode picks at high frequencies. By modeling the dispersion effect for linear velocity gradient models with different average Vs, we find that for $\mathrm{Vs} 30<360 \mathrm{~m} / \mathrm{s}$, the road surface has a significant effect on the dispersion data and should be accounted for by incorporating a high-velocity road layer into the inverse model. For high-velocity sediments $(\mathrm{Vs} 30>760 \mathrm{~m} / \mathrm{s})$, the road surface has a less significant effect, but incorporating a high-velocity road layer in the inverse model can still improve the Vs model.

\section{Data and Resources}

- R/T dispersion forward modeling code https://github.com/yiran06/mat_disperse (last accessed August 2019)

- Waveforms modeling using "Basic Seismic Utilities Software" https://scholarworks.boisestate. edu/geo_data/3/ (last accessed August 2019)

- SCPT data provide by Utah Geological Survey https://geology .utah.gov/about-us/geologic-programs/ geologic-hazards-program/for-consultants-and-design-professionals/community-velocity-model-cvm-anc shallow-shear-wave-velocity-data/ (last accessed August 2019)

- Seismic data uploaded as IRIS assembled data set 19-019: Salt Lake 2017 Land Streamer profiling DOI: 10.7914/SN/XQ_2017 https://doi.org/10.7914/SN/XQ_2017 (last accessed August 2019)

\section{References}

Aki, K. (1993). Local site effects on weak and strong ground motion. Tectonophysics, 218(1-3):93-111.

Andrus, R. D. and Stokoe II, K. H. (2000). Liquefaction resistance of soils from shear-wave velocity. Journal of geotechnical and geoenvironmental engineering, 126(11):1015-1025.

BSSC, B. S. S. C. (2009). Nehrp recommended seismic provisions for new buildings and other structures (fema p-750). Washington, DC: Federal Emergency Management Agency. 
This is an author-produced, peer-reviewed version of this article. The final, definitive version of this document can be found online at Bulletin of the Seismological Society of America, published by Seismological Society of America. Copyright restrictions may apply. https:// doi.org/10.1785/0120190120. The content of this document may vary from the final published version.

Dal Moro, G., Pipan, M., and Gabrielli, P. (2007). Rayleigh wave dispersion curve inversion via genetic algorithms and marginal posterior probability density estimation. Journal of Applied Geophysics, 61(1):3955.

Foti, S., Hollender, F., Garofalo, F., Albarello, D., Asten, M., Bard, P.-Y., Comina, C., Cornou, C., Cox, B., Di Giulio, G., et al. (2018). Guidelines for the good practice of surface wave analysis: a product of the interpacific project. Bulletin of Earthquake Engineering, 16(6):2367-2420.

Inazaki, T. (2006). High-resolution s-wave reflection survey in urban areas using a woven belt type land streamer. In Near Surface 2006-12th EAGE European Meeting of Environmental and Engineering Geophysics.

Kayen, R., Moss, R., Thompson, E., Seed, R., Cetin, K., Kiureghian, A. D., Tanaka, Y., and Tokimatsu, K. (2013). Shear-wave velocity-based probabilistic and deterministic assessment of seismic soil liquefaction potential. Journal of Geotechnical and Geoenvironmental Engineering, 139(3):407-419.

Kennett, B. and Kerry, N. (1979). Seismic waves in a stratified half space. Geophys. J. R. Astron. Soc., $57: 557-583$.

Kennett, B. L. (2009). Seismic Wave Propagation in Stratified Media. Australian National University E Press.

Kennett, B. L. N. (1974). Reflections, rays, and reverberations. Bull. Seismol. Soc. Am., 64(6):1685-1696.

Kramer, S. L. (1996). Geotechnical earthquake engineering. Prentice Hall, Inc.

Liberty, L. M., Clair, J. S., and Gribler, G. (2018). Seismic land-streamer data reveal complex tectonic structures beneath salt lake city. In SEG Technical Program Expanded Abstracts 2018, pages 2662-2666. Society of Exploration Geophysicists.

Liberty, L. M. and Gribler, G. (2014). Development of land streamer technologies for estimating shear wave velocities in an urban environment.

McDonald, G. N. and Ashland, F. X. (2008). Earthquake Site Conditions in the Wasatch Front Corridor, Utah, volume 125. Utah Geological Survey.

McMechan, G. A. and Yedlin, M. J. (1981). Analysis of dispersive waves by wave field transformation. Geophysics, 46(6):869-874.

Michaels, P. (2018). Basic seismic utilities software. https://scholarworks.boisestate.edu/geo_data/3. Accessed: 2019/01/10. 
Michaels, P. and Smith, R. B. (1997). Surface wave inversion by neural networks (radial basis functions) for engineering applications. The Journal of Environmental and Engineering Geophysics, 2(1):65-76.

Moss, R. E. S. (2008). Quantifying measurement uncertainty of thirty-meter shear-wave velocity. Bulletin of the Seismological Society of America, 98(3):1399-1411.

Nazarian, S., Stokoe, I., Kenneth, H., Briggs, R. C., and Rogers, R. (1988). Determination of pavement layer thicknesses and moduli by sasw method. Transportation Research Record, (1196).

Park, C. B., Miller, R. D., and Xia, J. (1999). Multichannel analysis of surface waves. Geophysics, 64(3):800.

Pei, D., Louie, J. N., and Pullammanappallil, S. K. (2008). Improvements on Computation of Phase Velocities of Rayleigh Waves Based on the Generalized R/T Coefficient Method. Bull. Seismol. Soc. Am., 98(1):280287.

Pei, D., Louie, J. N., and Pullammanappallil, S. K. (2009). Erratum to improvements on computation of phase velocities of rayleigh waves based on the generalized $\mathrm{r} / \mathrm{t}$ coefficient method. Bulletin of the Seismological Society of America, 99(4):2610-2611.

Personius, S. F. and Scott, W. E. (1992). Surficial geologic map of the salt lake city segment and parts of adjacent segments of the wasatch fault zone, davis, salt lake, and utah counties, utah. Technical report.

Pugin, A. J., Larson, T. H., Sargent, S. L., McBride, J. H., and Bexfield, C. E. (2004). Near-surface mapping using sh-wave and p-wave seismic land-streamer data acquisition in illinois, us. The Leading Edge, 23(7):677-682.

Robertson, P. K., Campanella, R., Gillespie, D., and Rice, A. (1986). Seismic cpt to measure in situ shear wave velocity. Journal of Geotechnical Engineering, 112(8):791-803.

Song, Y.-Y., Castagna, J. P., Black, R. A., and Knapp, R. W. (1989). Sensitivity of near-surface shear-wave velocity determination from rayleigh and love waves. In SEG Technical Program Expanded Abstracts 1989, pages 509-512. Society of Exploration Geophysicists.

Stephenson, W. J., Louie, J. N., Pullammanappallil, S., Williams, R., and Odum, J. K. (2005). Blind shear-wave velocity comparison of remi and masw results with boreholes to $200 \mathrm{~m}$ in santa clara valley: implications for earthquake ground-motion assessment. Bulletin of the Seismological Society of America, 95(6):2506-2516. 
This is an author-produced, peer-reviewed version of this article. The final, definitive version of this document can be found online at Bulletin of the Seismological Society of America, published by Seismological Society of America. Copyright restrictions may apply. https:// doi.org/10.1785/0120190120. The content of this document may vary from the final published version.

Van der Veen, M., Spitzer, R., Green, A., and Wild, P. (2001). Design and application of a towed land-streamer system for cost-effective 2-d and pseudo-3-d shallow seismic data acquisition. Geophysics, 66(2):482-500.

Van Der Veen, M., Wild, P., Spitzer, R., and Green, A. (1999). Design characteristics of a seismic land streamer for shallow data acquisition. In 61st EAGE Conference and Exhibition.

Wills, C., Petersen, M., Bryant, W., Reichle, M., Saucedo, G., Tan, S., Taylor, G., and Treiman, J. (2000). A site-conditions map for california based on geology and shear-wave velocity. Bulletin of the Seismological Society of America, 90(6B):S187-S208.

Yamanaka, H. and Ishida, H. (1996). Application of genetic algorithms to an inversion of surface-wave dispersion data. Bulletin of the Seismological Society of America, 86(2):436-444.

Yoder, E. J. and Witczak, M. W. (1975). Principles of pavement design. John Wiley \& Sons. 


\section{${ }_{367}$ Author Address}

Gabriel Gribler

1910 University Drive

Boise, Idaho 83725

USA

Lee M. Liberty

1910 University Drive

Boise, Idaho 83725

USA

T. Dylan Mikesell

1910 University Drive

Boise, Idaho 83725

USA 


\section{Figure Captions}

1 Vs estimates from SCPT measurements at borehole 146 (black) and surface-seismic MASW; the solid blue line represents the average Vs profile from the six one dimensional MASW linearized inversions near borehole 146. The surface seismic data are located within about $10 \mathrm{~m}$ of borehole 146. Dotted blue lines are the \pm one standard deviation. Note that the smoothed linearized inversion does not accurately reconstruct velocity inversions. Dashed (red) line represents the simplified seven-layer SCPT-derived model used in the forward models

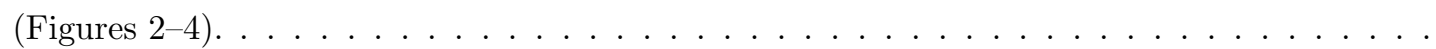

2 Summed power spectra plot between 3 to $40 \mathrm{~Hz}$ for modeled data with a native material road surface (solid black), a $25 \mathrm{~cm}$ rigid $(1300 \mathrm{~m} / \mathrm{s}$ ) road surface (dot-dashed red), and a $10 \mathrm{~cm}$ flexible $(800 \mathrm{~m} / \mathrm{s})$ road surface $($ dashed cyan $) \ldots \ldots \ldots \ldots \ldots \ldots \ldots$

3 MASW-derived dispersion images for the seven-layer velocity model (dashed-red line in Figure 1) with different road surface properties: (a) native material seven layer model, (b) an added $25 \mathrm{~cm}$ thick stiff road surface layer $(\mathrm{Vs}=1300 \mathrm{~m} / \mathrm{s}$ ), (c) an added $10 \mathrm{~cm}$ thick flexible road surface $(\mathrm{Vs}=800 \mathrm{~m} / \mathrm{s})$. Lighter colors represent higher coherence and lines represent theoretical dispersion curves, which include the fundamental mode and the first two higher mode Rayleigh waves (dashed-black lines). (d) Dispersion image from seismic data collected at the location of SCPT borehole 146. The fundamental mode dispersion curves from (a), (b), and (c) are overlain on (d). Black asterisks indicate automatic dispersion picks tracking the highest coherence for each frequency. The eight-layer road surface dispersion model curves show higher phase velocities across all frequencies when compared to the seven-layer native material model curve. . . . . . . . . . . . . . . . . . . . . . . . . . . . .

4 Inversion results for native material (a), no road included (b) and road included (c). Black solid lines in a-c is the true model, solid colored lines are the average results from 12 individual inversions and dash colored lines represent one standard deviation of the inversion results. (d) Comparison between SCPT-derived and inverted Vs profiles using a genetic algorithm inversion of the synthetic dispersion curves. (e) Depth versus time-averaged Vs. For instance, Vs at 30 meters depth corresponds to Vs30. (f) Percent difference in average Vs with depth between the seven-layer starting model and inverse models. Line styles and colors in (e) and (f) correspond to those in (d). The table summarizes the differences between inversion results

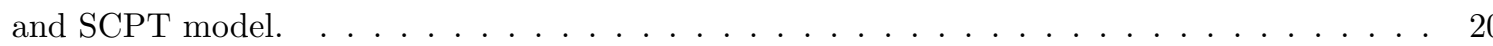


This is an author-produced, peer-reviewed version of this article. The final, definitive version of this document can be found online at Bulletin of the Seismological Society of America, published by Seismological Society of America. Copyright restrictions may apply. https:// doi.org/10.1785/0120190120. The content of this document may vary from the final published version.

5 (a) Topographic map showing seismic profile location (solid red line) along 700 South in Salt Lake City, Utah, USA. Black diamonds indicate SCPT measurement locations for boreholes 146 and 147. Black dots near borehole 146 represent the geophone array length for our (Figure 3d) comparison. (b) Vs30 estimates from shot gathers along the 700 South seismic profile (a). Dotted (blue) line with circular markers represents inversion results with no road layer included in the inversion. Error bars represent one standard deviation calculated from 57 adjacent dispersion curves. Dotted (red) line with triangular markers represent GA inversion results with a rigid road surface included in the inversion. Two diamonds represent SCPTderived Vs30 at boreholes 146 and 147. We observe a systematic overestimation of Vs30 when when the layer is ignored compared to the inversion where the road layer is included. . . . . . 21

6 Dispersion curve percent overestimation due to $25 \mathrm{~cm}$ thick rigid $(1300 \mathrm{~m} / \mathrm{s})$ road surface for different Vs30 measurements (NEHRP classes B-E). Velocity profiles constitute a constant Vs gradient of $+4 \mathrm{~m} / \mathrm{s}$ per meter for the upper 100 meters with different surface velocities $\mathrm{V}_{o}$. Two dot-dashed (red) lines denote dispersion differences due to a $10 \mathrm{~cm}$ thick flexible $(800 \mathrm{~m} / \mathrm{s})$ road surface layer. Table shows the NEHRP classfication of Wills et al. (2000) and velocity parameters for each model. . . . . . . . . . . . . . . . . . . . . . . . . . . . 


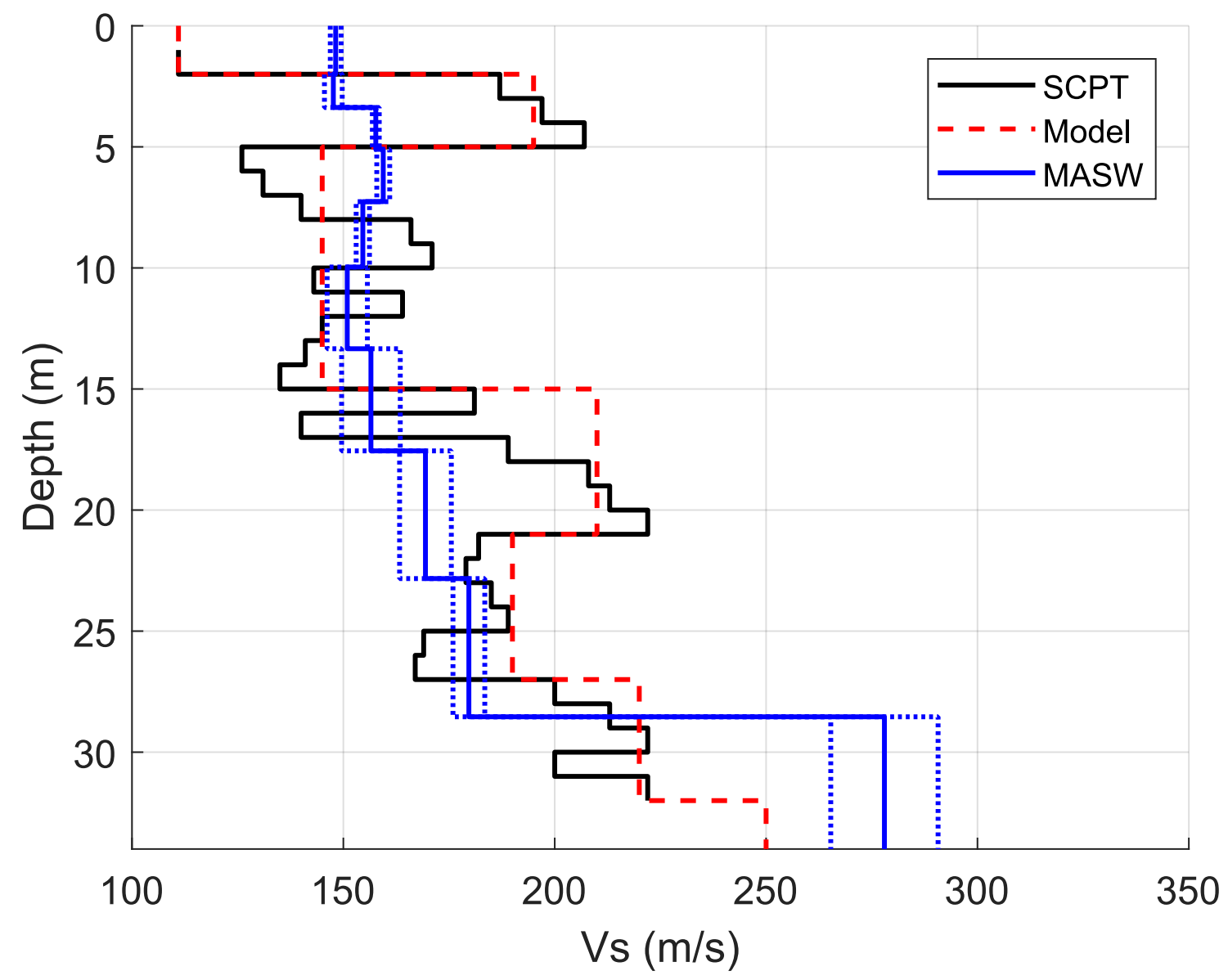

Figure 1: Vs estimates from SCPT measurements at borehole 146 (black) and surface-seismic MASW; the solid blue line represents the average Vs profile from the six one dimensional MASW linearized inversions near borehole 146. The surface seismic data are located within about $10 \mathrm{~m}$ of borehole 146 . Dotted blue lines are the \pm one standard deviation. Note that the smoothed linearized inversion does not accurately reconstruct velocity inversions. Dashed (red) line represents the simplified seven-layer SCPT-derived model used in the forward models (Figures 2-4). 
This is an author-produced, peer-reviewed version of this article. The final, definitive version of this document can be found online at Bulletin of

the Seismological Society of America, published by Seismological Society of America. Copyright restrictions may apply. https://

doi.org/10.1785/0120190120. The content of this document may vary from the final published version.

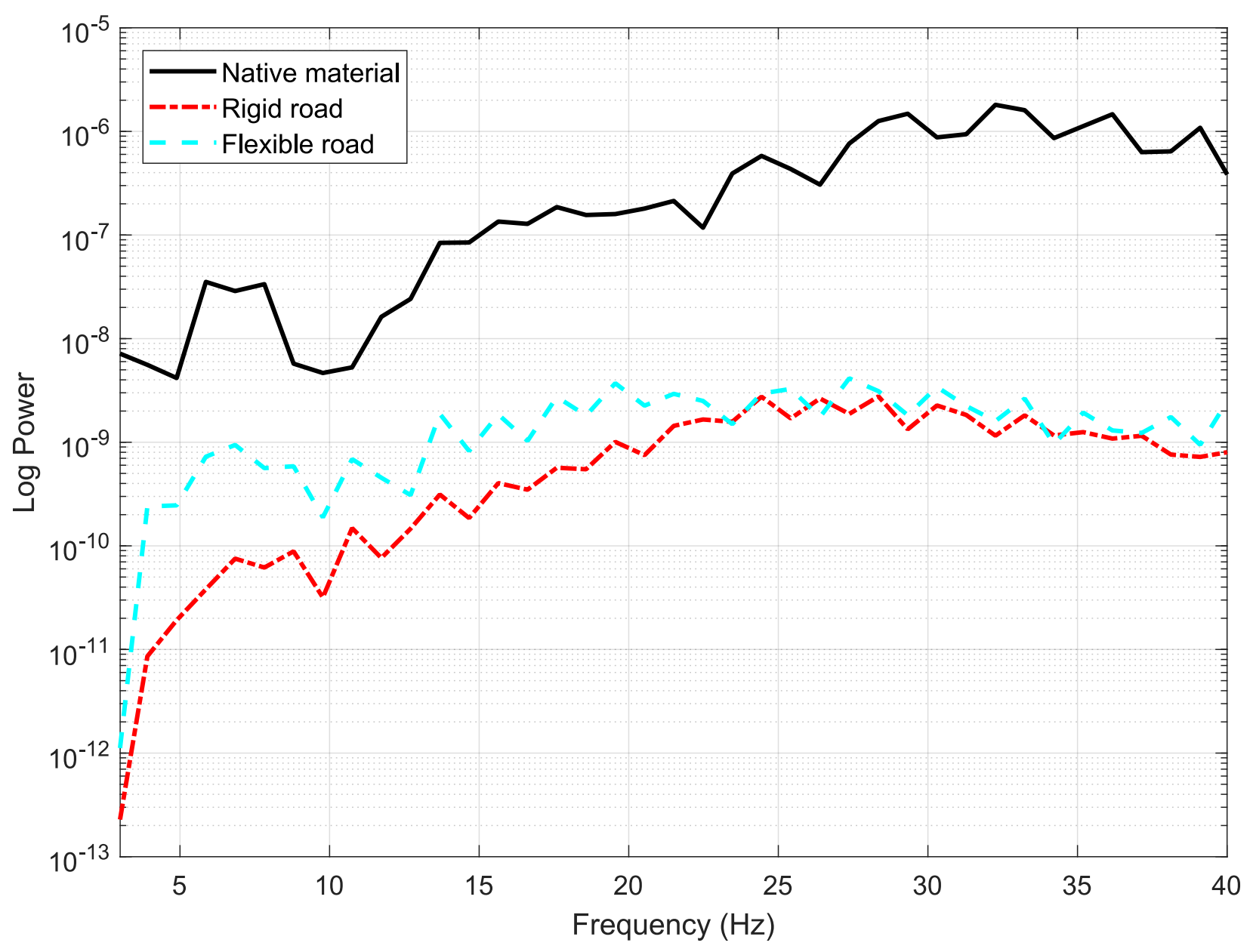

Figure 2: Summed power spectra plot between 3 to $40 \mathrm{~Hz}$ for modeled data with a native material road surface (solid black), a $25 \mathrm{~cm}$ rigid $(1300 \mathrm{~m} / \mathrm{s})$ road surface (dot-dashed red), and a $10 \mathrm{~cm}$ flexible $(800 \mathrm{~m} / \mathrm{s}$ ) road surface (dashed cyan). 


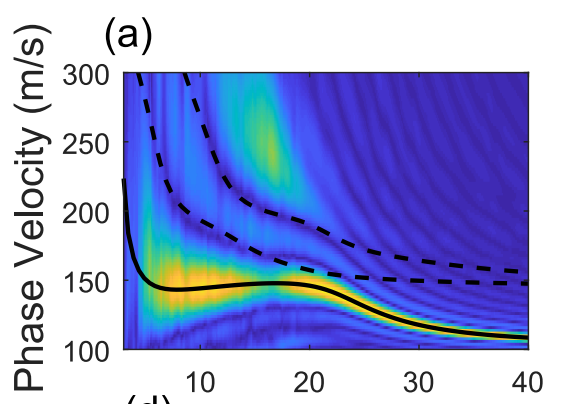

(b)

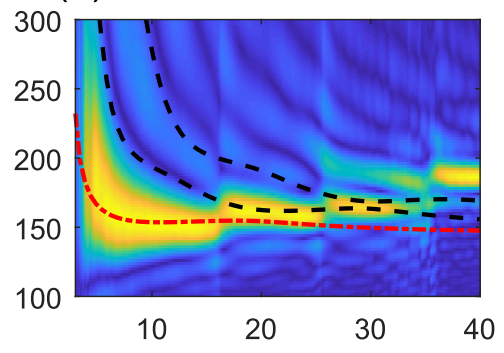

(c)

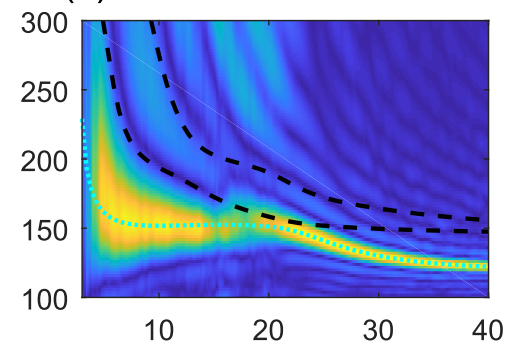

(d)

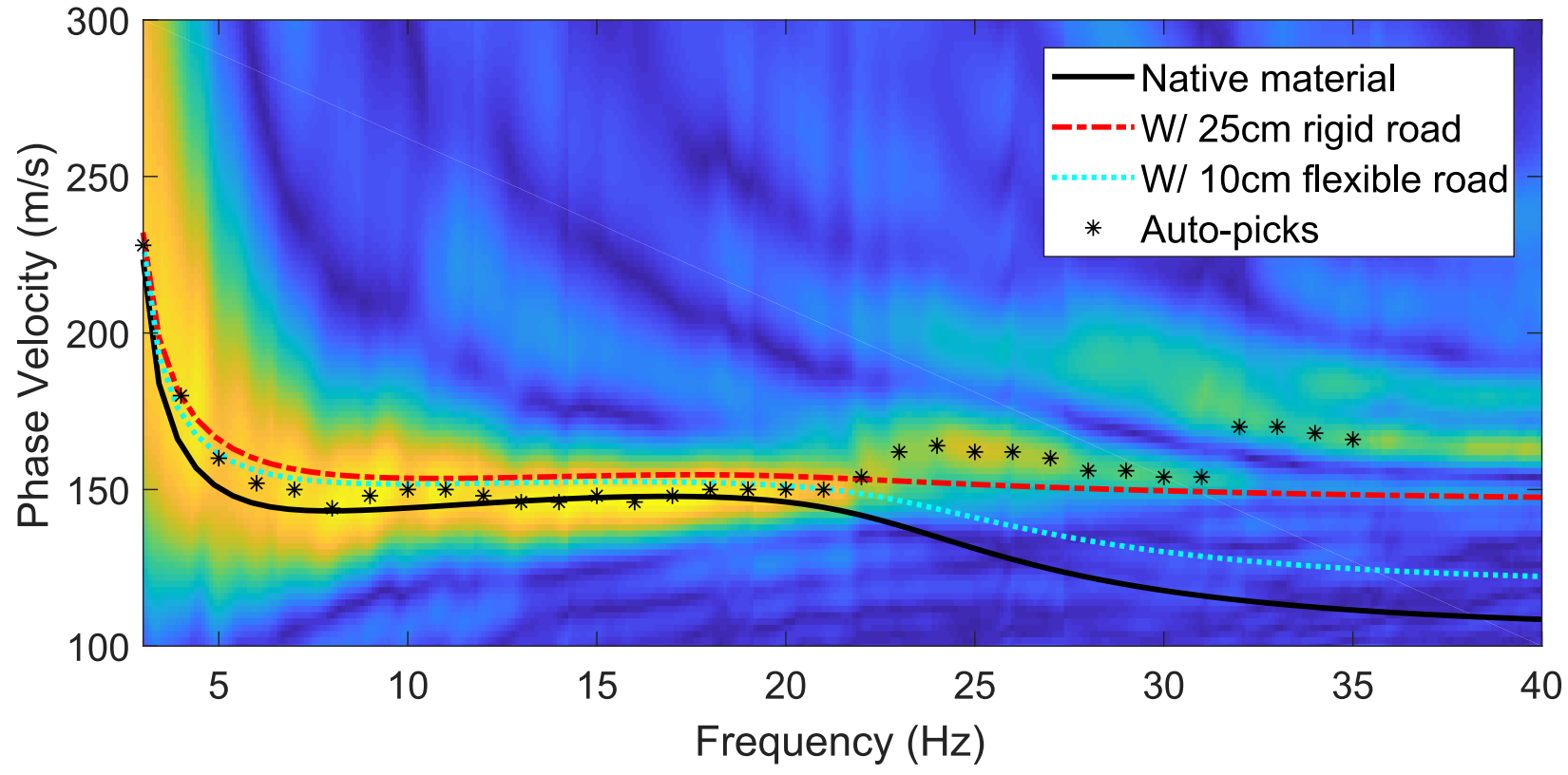

Figure 3: MASW-derived dispersion images for the seven-layer velocity model (dashed-red line in Figure 1) with different road surface properties: (a) native material seven layer model, (b) an added $25 \mathrm{~cm}$ thick stiff road surface layer $(\mathrm{Vs}=1300 \mathrm{~m} / \mathrm{s}),(\mathrm{c})$ an added $10 \mathrm{~cm}$ thick flexible road surface $(\mathrm{Vs}=800 \mathrm{~m} / \mathrm{s})$. Lighter colors represent higher coherence and lines represent theoretical dispersion curves, which include the fundamental mode and the first two higher mode Rayleigh waves (dashed-black lines). (d) Dispersion image from seismic data collected at the location of SCPT borehole 146. The fundamental mode dispersion curves from (a), (b), and (c) are overlain on (d). Black asterisks indicate automatic dispersion picks tracking the highest coherence for each frequency. The eight-layer road surface dispersion model curves show higher phase velocities across all frequencies when compared to the seven-layer native material model curve. 
(a)

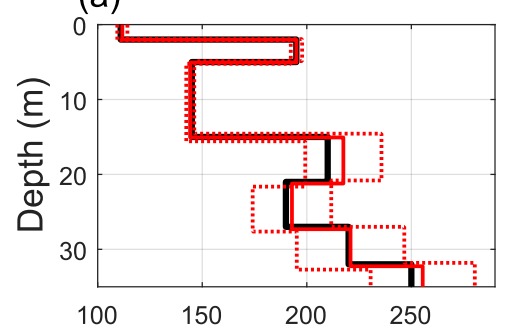

(d) (b)

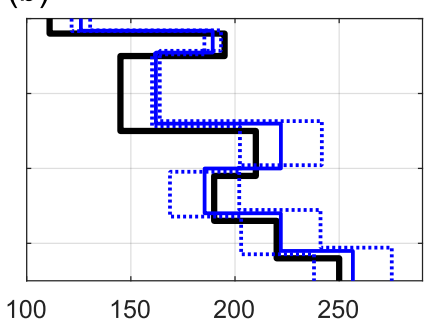

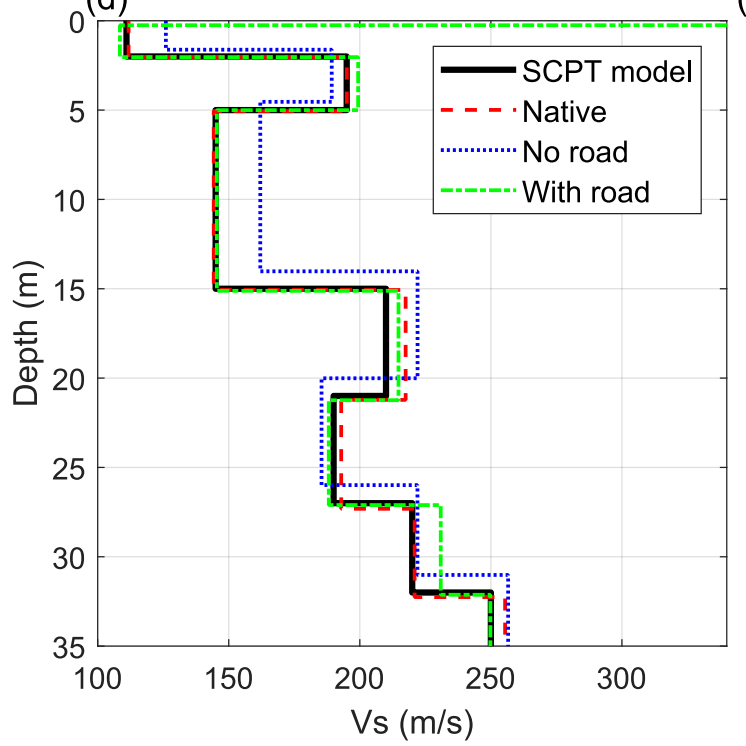

(e)

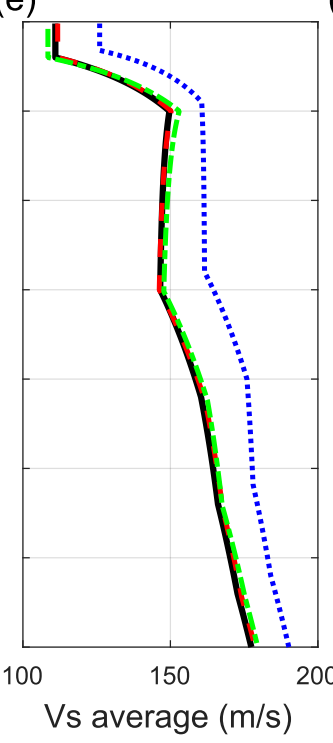

(c)

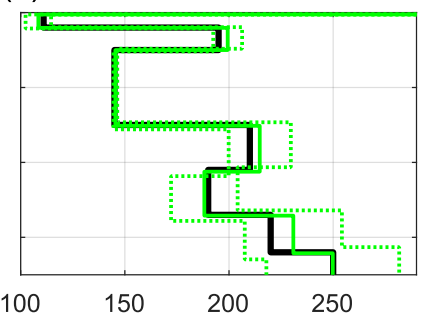

(f)

\begin{tabular}{|l|c|c|c|c|}
\hline Line style & Solid & Dashed (red) & Dotted (blue) & Dot-dashed (green) \\
\hline Data surface & Model & Native & Rigid & Rigid \\
\hline Inversion surface & Model & Native & Native & Rigid \\
\hline Vs30 & $170 \mathrm{~m} / \mathrm{s}$ & $172 \mathrm{~m} / \mathrm{s}$ & $183 \mathrm{~m} / \mathrm{s}$ & $173 \mathrm{~m} / \mathrm{s}$ \\
\hline Vs30 \% difference & $0 \%$ & $1.1 \%$ & $7.6 \%$ & $1.7 \%$ \\
\hline
\end{tabular}

Figure 4: Inversion results for native material (a), no road included (b) and road included (c). Black solid lines in a-c is the true model, solid colored lines are the average results from 12 individual inversions and dash colored lines represent one standard deviation of the inversion results. (d) Comparison between SCPTderived and inverted Vs profiles using a genetic algorithm inversion of the synthetic dispersion curves. (e) Depth versus time-averaged Vs. For instance, Vs at 30 meters depth corresponds to Vs30. (f) Percent difference in average Vs with depth between the seven-layer starting model and inverse models. Line styles and colors in (e) and (f) correspond to those in (d). The table summarizes the differences between inversion results and SCPT model. 
(a)
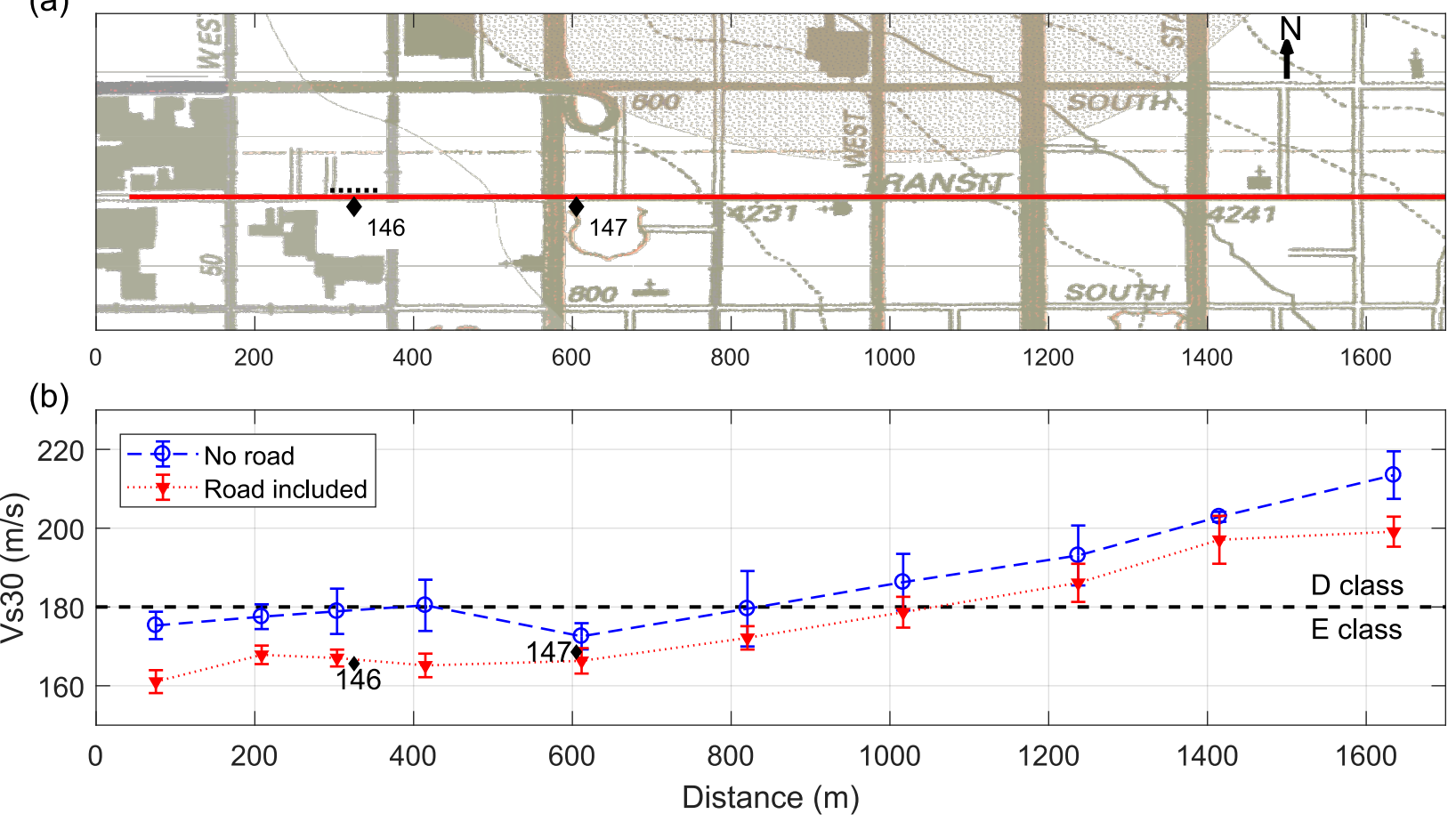

Figure 5: (a) Topographic map showing seismic profile location (solid red line) along 700 South in Salt Lake City, Utah, USA. Black diamonds indicate SCPT measurement locations for boreholes 146 and 147. Black dots near borehole 146 represent the geophone array length for our (Figure 3d) comparison. (b) Vs30 estimates from shot gathers along the 700 South seismic profile (a). Dotted (blue) line with circular markers represents inversion results with no road layer included in the inversion. Error bars represent one standard deviation calculated from 5-7 adjacent dispersion curves. Dotted (red) line with triangular markers represent GA inversion results with a rigid road surface included in the inversion. Two diamonds represent SCPT-derived Vs30 at boreholes 146 and 147. We observe a systematic overestimation of Vs30 when when the layer is ignored compared to the inversion where the road layer is included. 
This is an author-produced, peer-reviewed version of this article. The final, definitive version of this document can be found online at Bulletin of the Seismological Society of America, published by Seismological Society of America. Copyright restrictions may apply. https:// doi.org/10.1785/0120190120. The content of this document may vary from the final published version.

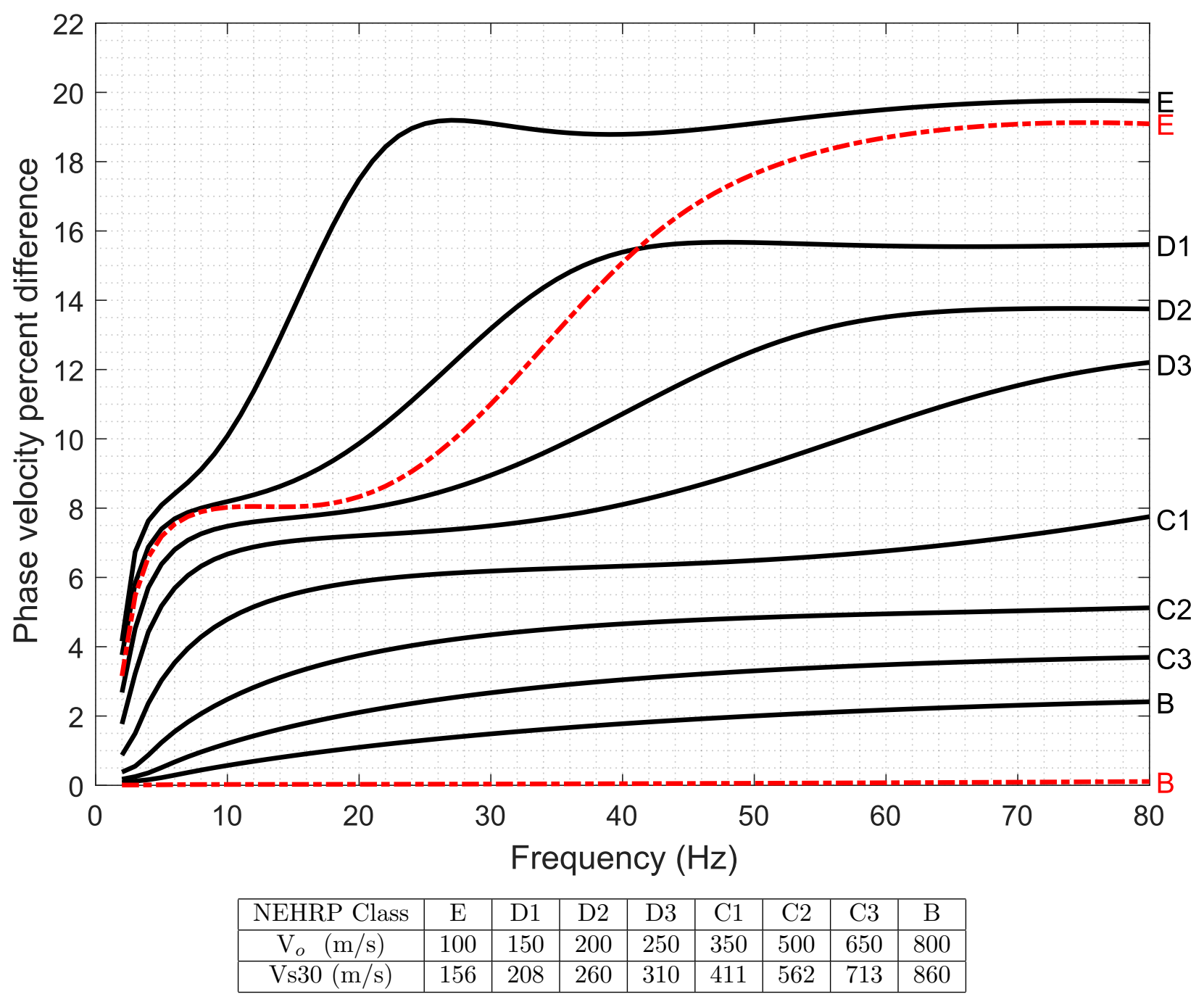

Figure 6: Dispersion curve percent overestimation due to $25 \mathrm{~cm}$ thick rigid $(1300 \mathrm{~m} / \mathrm{s})$ road surface for different Vs30 measurements (NEHRP classes B-E). Velocity profiles constitute a constant Vs gradient of $+4 \mathrm{~m} / \mathrm{s}$ per meter for the upper 100 meters with different surface velocities $\mathrm{V}_{o}$. Two dot-dashed (red) lines denote dispersion differences due to a $10 \mathrm{~cm}$ thick flexible $(800 \mathrm{~m} / \mathrm{s})$ road surface layer. Table shows the NEHRP classfication of Wills et al. (2000) and velocity parameters for each model. 